\title{
Agentes de deterioro y alteraciones de las pinturas murales "in situ"
}

\section{Palabras clave:}

Pintura mural / Restauración / Agentes de deterioro

Los valores y características que distinguen a la pintura mural de otras formas artísticas de la pintura son fundamentales a la hora de entender la problemática especifica que presenta su conservación y de determinar cuales son sus agentes de deterioro y sus alteraciones, a través del conocimiento de sus técnicas de ejecución y sus materiales constitutivos.

El marco de la pintura mural es la propia arquitectura, en la cual el espectador está incluido. Cuando en la pintura mural aparece un marco, solo sirve para separar distintas escenas de una serie, o para dar ritmo a la pared o como un "trompe-l'oeil", imitando el marco de un cuadro. Por lo tanto, el marco de una pintura mural puede ser tanto la arquitectura que la rodea, como una ilusión pintada. Cuando su íntima relación con la arquitectura se pierde, la pintura mural pierde su papel específico y pasa a ser como una pintura de caballete o un tapiz.

La arquitectura ha necesitado siempre el color y la decoración figurativa esculpida o pintada, y es un serio error pensar que las artes están divididas según las técnicas empleadas en su ejecución. En cada período, color y decoración pintada han sido observados, desde el inicio de la obra, como parte integral de la estructura arquitectónica, a la que definen y dan significado. Y si hiciésemos un recorrido por la historia del arte desde el principio de los tiempos hasta nuestros días, observaríamos que separar la decoración figurativa y el color, de la arquitectura sería pues, la destrucción de una unidad conceptual, histórica y estética.

De cualquier manera, tenemos que entender que, cuando nos enfrentamos al diagnóstico del estado de

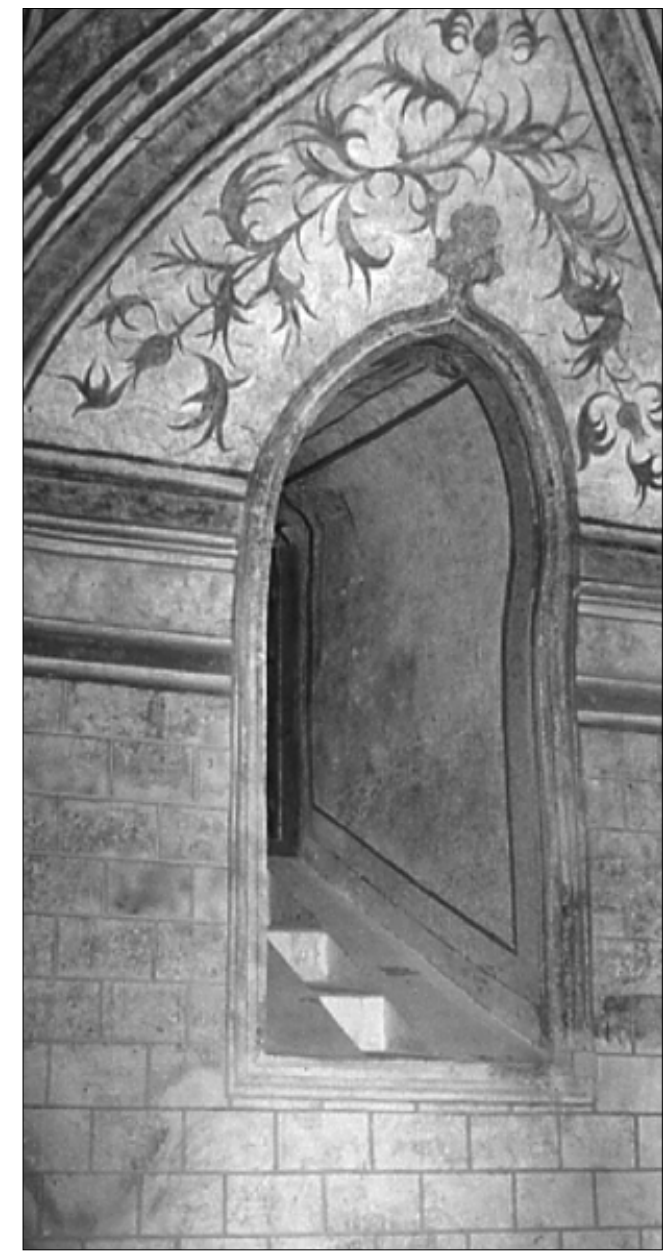

Pinturas murales de la Sala Capitular del Real Monasterio de Guadalupe, Caceres. conservación y a la intervención de una pintura mural, estamos haciendo referencia solamente a una parte del vasto entramado en el que está situada y, al cual constantemente, tenemos la obligación de dirigirnos $y$, tener en cuenta factores tales como: la estabilidad de la estructura, la humedad, la iluminación, el clima, etc. Por tanto, es esencial hacer el planteamiento del diagnóstico y tratamiento atendiendo al contexto indisociable entre la pintura mural y el entorno donde se encuentra. Por lo cual la colaboración interdisciplinar entre expertos de diferentes materias (arquitectura, historia, química y física, restauración, etc.) es lo recomendable y deseable para garantizar un trabajo impecable, riguroso y con las mayores garantías de éxito.

En pintura mural las alteraciones que se pueden observar son debidas a muchos factores diferentes. Por lo general estos agentes de deterioro actúan en conjunto y potenciándose, a menudo, unos a otros. Los daños provocados en este tipo de obras, se manifiestan casi siempre cierto tiempo después de haber comenzado el problema y también, su efecto 
normalmente persiste, tras haber tomado las medidas de necesarias para su neutralización o eliminación, durante otro periodo de tiempo. Dadas las particulares características que rodean a la pintura mural, es decir, su interrelación con la pared o muro y éstos a su vez con el inmueble en el que se hallan situados, es necesario reconstruir la historia material del edificio, tomando nota de las modificaciones e intervenciones que haya sufrido para intentar establecer la relación causa-efecto en la aparición de los daños observados. Solamente, y tras una investigación histórico-técnica en este sentido, se pueden establecer las bases de un diagnóstico y tratamiento eficaces y prever las actuaciones que garanticen la erradicación de los agentes causantes del deterioro o por lo menos reducir los efectos dañinos de los mismos, con objeto de mantener su permanencia y aumentar su protección.

Destacan tres aspectos principales en la pintura mural que caracterizan su comportamiento bajo el prisma conservativo:

I. Los materiales constitutivos poseen una porosidad elevada, lo que los hace fácilmente accesibles a todos aquellos agentes externos que son potencialmente nocivos o agresivos sea en fase líquida o gaseosa(polución atmosférica, vapor de agua, soluciones salinas, etc.).

2. La pintura mural está en un sistema químico-físico fundamentalmente abierto, incluso después de una intervención, consecuencia directa de su contacto permanente con la estructura subyacente y adyacente, estructura que a su vez no está aislada sino constantemente implicada en un complejo de fenómenos físicos, químicos, biológicos, etc.

3. El microclima en contacto con la pintura mural, que generalmente se encuentra situada en edificios monumentales, no admite casi nunca un adecuado control autónomo.

Por todo lo cual, y resumiendo los tres puntos anteriores, se puede afirmar que la porosidad de los elementos y materiales constitutivos de la pintura mural crean una situación de vulnerabilidad de la misma frente a todo tipo de agresiones, difícilmente encontrada a este nivel en cualquier otro tipo de obra de arte. El contacto directo con los restantes elementos que conforman el espacio donde se encuentra, favorece la afluencia de sustancias de naturaleza muy variada generalmente en forma de solución, que en la mayoría de los casos son muy peligrosas para la integridad de los materiales constitutivos.

De todas formas, las principales alteraciones que podemos observar en las pinturas murales están debidas a fenómenos naturales, de naturaleza física, química y biológica, desencadenados por los factores termohigrométricos que determinan las variaciones térmicas y la presencia de agua en cualquiera de sus estados de agregación.
La acción de la temperatura está en el origen de las deformaciones diferenciales de la obra debido a los diferentes coeficientes de dilatación de los materiales constitutivos. Las variaciones de volumen experimentadas por cada componente favorecen el desarrollo de tensiones mecánicas internas que pueden provocar fracturas del conjunto.

Pero sin lugar a dudas, la causa de alteración de las pinturas murales más importante es la humedad debido a dos factores determinantes. Por un lado la frecuencia de su aparición como causa de alteración (problemas de humedad en los edificios) y por otro, por su efecto como catalizador, intermediario y potenciador de muchos deterioros (ataques biológicos y alteraciones debidas a reacciones químicas producidas por la presencia del agua). Por tanto y siguiendo el esquema planteado por los Mora estableceremos la siguiente clasificación:

- alteraciones debidas a la humedad o favorecidas por ella.

- alteraciones debidas a causas físicas diferentes a la humedad.

- alteraciones debidas a los materiales constitutivos utilizados por el artista o a defectos de la técnica empleada.

- alteraciones debidas a tratamientos inadecuados.

La humedad es la principal causa de alteración de las pinturas murales y por tanto la identificación de su origen y la eliminación o neutralización del mismo será premisa fundamental antes de afrontar cualquier tratamiento con las debidas garantías.

Dependiendo de su origen, la humedad de las paredes puede ser clasificada en cinco tipos diferentes:

I. por infiltración: debida al agua filtrada a través de los techos, de terrazas o por defectos en la infraestructura o en los sistemas de drenaje para el agua de Iluvia; o en las pinturas murales que se encuentran en el exterior por el agua de lluvia.

2. por capilaridad: por el agua procedente del suelo.

3. por condensación: de la humedad del aire sobre paredes frías.

4. humedad interna producida por la presencia de materiales higroscópicos.

5. humedad procedente del aire húmedo que sube desde el suelo.

El examen de la estructura del edificio y la determinación del origen de la fuente de humedad es fundamental a la hora de aplicar cualquier tipo de tratamiento. Hay que tener en cuenta factores tales como la humedad relativa, la humedad de los muros, la temperatura del aire en el interior y el exterior del edificio, la distribución y concentración de la humedad en las paredes y la temperatura de las paredes entre otros. 
De todos los procesos de alteración favorecidos o iniciados por la presencia de humedad hay que destacar la migración y cristalización de sales. Se ha escrito mucho sobre los mecanismos destructivos de las sales en los morteros y en la película pictórica, pero vale la pena prestar atención sobre aquellos aspectos que afectan directamente al plano conservativo. Es bien sabido que una sal puede cristalizar solamente cuando la concentración de la solución supera la saturación, y salvo algunas excepciones, las soluciones que están presentes en los morteros son muy diluidas y para llegar a los valores de saturación necesitan una gran evaporación. En pintura mural el lugar donde se produce la evaporación mas alta es la superficie pictórica, por lo que se convierte en el lugar ideal para el desarrollo de este proceso de cristalización, y donde primero se puede observar este problema.

Examinando la naturaleza y los procesos desarrollados, por los diferentes agentes o materiales que llegan a los morteros de la pintura mural, es necesario destacar globalmente a las sustancias salinas, que acceden hasta la superficie pictórica por tres vías principalmente:

a) desde el suelo, el muro o la pared y debido a la porosidad de las mismas, las sales pueden llegar a los morteros y a la película pictórica diluidas en forma de solución acuosa.

b) el depósito de partículas atmosféricas, acumula y fija en la superficie de la pintura no sólo substancias inertes, sino también compuestos activos en cuanto a solubilidad como el yeso, los nitratos y los cloruros.

c) la interacción producida por los contaminantes gaseosos de naturaleza ácida con el carbonato de calcio de los morteros, produce directamente sustancias salinas de lo más solubles.

Las dos primeras vías de acceso producen un aporte de sales del exterior, mientras que la tercera se produce a costa de uno de los materiales constitutivos de la propia pintura. Indistintamente de la manera por la cual se aproximen a la superficie, las sustancias salinas, como consecuencia de las variaciones microclimáticas, sufren una serie de cristalizaciones y solubilizaciones cíclicas, que independientemente de su magnitud producen efectos muy degradantes y nocivos para las pinturas. Dependiendo de la composición de las sales, el deterioro producido y la apreciación del mismo, varia sobre los morteros o sobre la superficie pictórica. Los más peligrosos son los sulfatos (de sodio, potasio, magnesio y calcio) porque según el nivel al que se produzca la cristalización producen una mayor pérdida de la cohesión de los materiales constitutivos; el sulfato cálcico, por ejemplo, puede cristalizar en superficie en forma de velo blanquecino o, en el interior de los morteros transformando el carbonato cálcico en sulfato cálcico, transformación que se da en ambientes con una polución elevada.
Por otro lado las sales solubles como los nitratos de sodio, potasio o calcio producen eflorescencias en la superficie pictórica que son relativamente fáciles de eliminar, por lo que su efecto mecánico en la cohesión de los materiales constitutivos es menor.

El carbonato cálcico no produce propiamente una disgregación o falta de cohesión en los materiales constitutivos, al ser generalmente uno de ellos, pero sí, unas costras superficiales o carbonataciones, que son muy difíciles de eliminar.

Otras sales que podemos encontrar en los morteros - película pictórica de las pinturas murales que se encuentran en lugares próximos al mar son los cloruros, en forma de depósito superficial transportado por el aire. En sí mismos, no tienen una gran acción mecánica sobre los materiales constitutivos, pero si favorecen la cristalización o solución de otras sales que puedan estar presentes tanto en los morteros como en la película pictórica. Por último, hay que mencionar a los silicatos, transportados por el agua de infiltración desde los materiales constitutivos del muro (cemento, ladrillos o arcillas) y que a largo plazo su efecto se manifiesta en forma de velo blanquecino muy opaco o en forma de costras asociados a otras sustancias como los carbonatos.

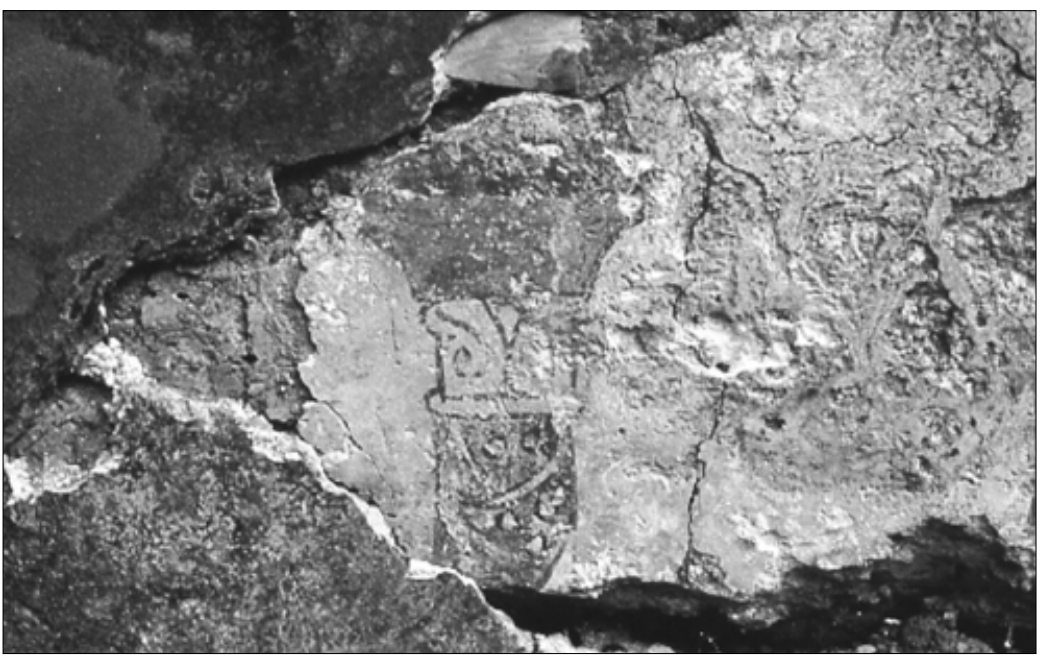

Por tanto y resumiendo las alteraciones que podemos observar producidas por efecto de las sales son:

- Velos blanquecinos superficiales.

Pinturas murales almohades del jardín del Patio Musulmán de la Consejería de Obras Públicas y Transportes de Sevilla

- Costras o carbonataciones.

- Eflorescencias.

- Pérdida de cohesión de los materiales constitutivos.

- Pérdidas de mortero y/o de película pictórica.

Las reacciones químicas producidas por la humedad en las pinturas murales son también, la causa de alteración de los pigmentos. Como consecuencia de estas reacciones, experimentan transformaciones fisico-químicas modificando su composición y como resultado de esto su color.

Las alteraciones de naturaleza biológica producidas por formas de vida microscópicas o macroscópicas 


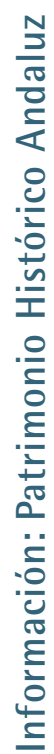

Pinturas almohades del jardín del Patio Musulmán de la Consejería de Obras Públicas y Transportes de Sevilla

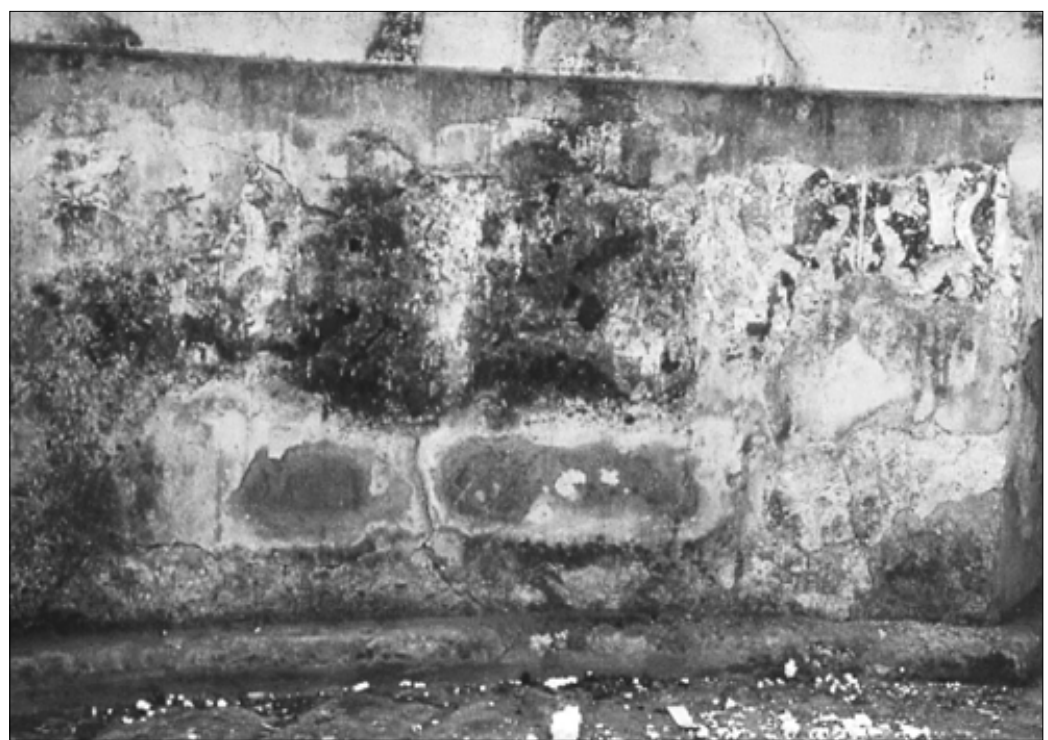
nes, se desarrollan rápidamente en ambientes cuya humedad relativa está por encima del $65 \%$, por lo cual, en lugares que están permanentemente húmedos podemos intuir su presencia. Estos organismos provocan daños físicos derivados de la actividad mecánica desarrollada durante su crecimiento y químicos debidos a su proceso metabólico. Se manifiestan en forma de puntos o de manchas, alterando la apariencia de los morteros y de la pintura y produciendo perdidas de color, dejando pequeños orificios tras su eliminación. Al inicio, este tipo de ataque es casi imperceptible, extendiéndose a zonas enteras de la pintura hasta la total destrucción de la misma.

La polución, es decir, los agentes atmosféricos potencian la desintegración de las pinturas murales. Estos agentes se pueden clasificar en dos clases: los naturales y los artificiales. Entre los naturales podemos citar las pequeñas partículas que pueden permanecer en suspensión en el aire, formadas normalmente por silice y carbonato cálcico procedentes del suelo y cloruros y/o sulfatos de sodio o potasio del agua del mar, que se depositan en la superficie de la pintura. Por otro lado el anhídrido carbónico, puede tener un origen natural o provenir de la respiración humana, lo que lo hace tremendamente dañino en espacios de dimensiones reducidas, donde es limitada la circulación del aire, y donde la afluencia de personas es elevada. La formación de ácido carbónico a partir de elevadas concentraciones de anhídrido carbónico en un medio húmedo da lugar, por reacción con el carbonato cálcico, a la transformación de este en bicarbonato cálcico, mucho más soluble en agua y que origina un empobrecimiento y debilidad de la estructura mural.

De los agentes artificiales o producidos por las actividades del hombre podemos destacar el anhídrido sulfuroso procedente, al igual que los óxidos de nitrógeno, de la combustión de materiales como el carbón - los hidrocarburos y que tras diferentes procesos forma en presencia de humedad ácido sulfúrico. Este entre las que podemos destacar, hongos, algas y líque-

hora de entender los mecanismos de deterioro que
se producen en forma de velos blanquecinos superficiales o costras.

Otras causas físicas de alteración de las pinturas murales son:

- El viento produce dos efectos, la erosión de la superficie en pinturas al exterior al ser portador de pequeñas partículas en suspensión y el incremento de la evaporación en superficie favoreciendo la cristalización de sales en esta zona.

- La luz, natural o artificial genera procesos de alteración de mayor o menor intensidad, no sólo aumentando la temperatura en las zonas donde inciden directamente, sino favoreciendo, especialmente por su componente ultravioleta, la 
degradación de los productos orgánicos - pigmentos o aglutinantes-.

- Depósitos superficiales, como polvo, hollín o deyecciones de insectos y animales como los pájaros o murciélagos pueden ocasionar un oscurecimiento de la superficie pictórica que incluso afecten a la legibilidad de las pinturas.

- El calor, de un incendio o incluso de las velas en los altares, produce la desintegración de los morteros o alteraciones de tono de ciertos pigmentos.

- Las vibraciones, producidas por el tráfico incrementan el riesgo de desprendimientos en pinturas cuyos morteros están ya debilitados.

- Factores mecánicos, imprevisibles como terremotos, asentamientos de los muros o del terreno, etc.

En cuanto a las alteraciones producidas por los materiales constitutivos o por defectos de la técnica de ejecución se puede mencionar en primer lugar el soporte. Si su constitución es heterogénea - ladrillos y piedra - la diferencia de porosidad y conductividad térmica favorecen la condensación en determinadas zonas, observándose manchas claras y obscuras en la superficie de la pintura. Por otro lado ya se ha visto anteriormente algunos de los problemas que presentan los morteros en función a su composición; problemas que se ven magnificados cuando se les suma algún defecto en las proporciones de aglutinante y carga o de impurezas o incluso en la forma de aplicación - por ejemplo en un mortero con demasiada carga la adhesión al soporte será menor, lo que favorecerá la caída del mismo. En cuanto a la película pictórica, los pigmentos utilizados deberán ser compatibles con la técnica pictórica - fresco, pinturas a la cal, temple, etc. ya que si no se pueden producir alteraciones cromáticas de los mismos, alteración que es irreversible.

Por último hay que mencionar las alteraciones producidas por la operaciones realizadas para ocultar las pinturas por alguna razón - estética, religiosa, higiénica, etc. - con diferentes capas de cal, temple o incluso de una nueva pared o un retablo. Y los tratamientos desafortunados que han sufrido muchas veces este tipo de obras por el desconocimiento de la compatibilidad de los materiales y técnicas empleados en intentar preservarlas, con los materiales constitutivos.

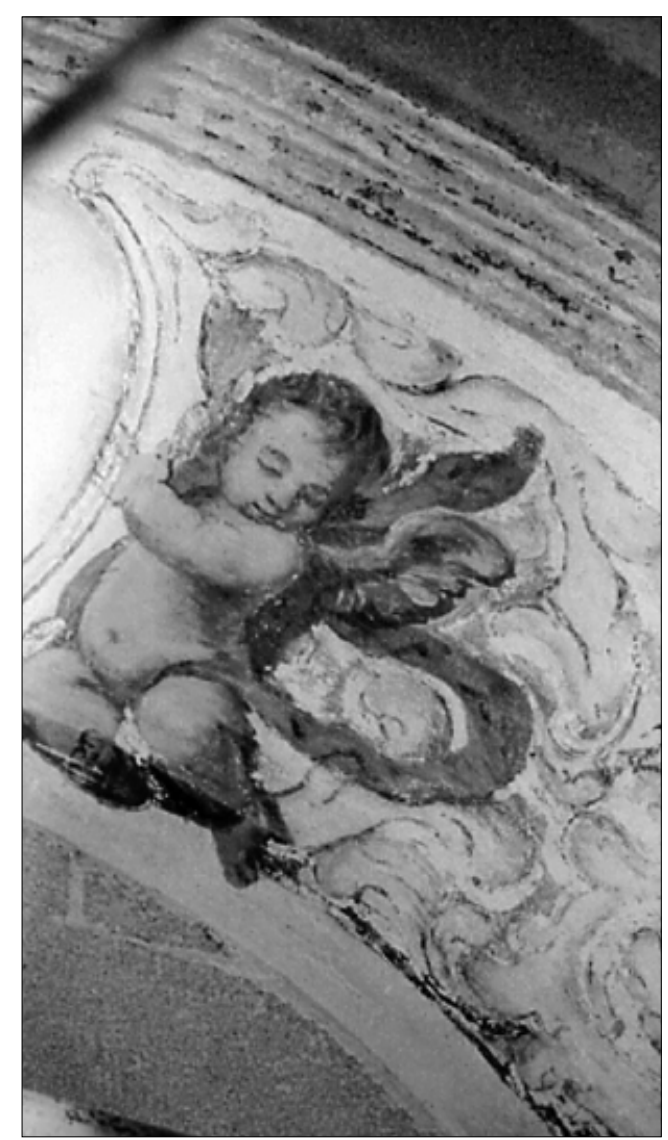

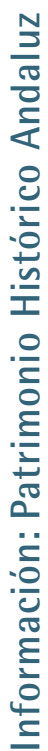

\section{Bibliografía}

AAVV., Fattori di Deterioramento. Corso sulla Manutenzione di Dipinti Murali-Mosaici-Stucchi. Dimos parte II-modulo I. Roma: Istituto Centrale Del Restauro. 1979.

AAV., Arte: materiales y conservación. Colección Debates sobre Arte.Vol.7. Madrid: Fundación Argentaria. 1988

AAVV. Le pitture murali. Firenze: Centro di. Opificio delle Pietre Duere e Laboratori di Restauro de Firenze. 1990.

MORA, P., Conservation of wall paintings. Butterworths. Serie's in conservation and museology. London, 1984.
Pinturas murales de la Capilla de los Ibarra del Hospital de las cinco LLagas, actual sede del Parlamento Andaluz, Sevilla 